\title{
EDUCAR MIRADAS EN RESISTENCIA A LA COLONIALIDAD DEL VER
}

\author{
RODRIGO ZÁRATE MOEDANO' \\ Universidad Veracruzana (México) / rzarate@uv.mx \\ Angélica HeRnández VÁSQuez ${ }^{2}$ \\ Universidad Veracruzana (México) / angelichernandez@uv.mx \\ KÁROLY MARIEL MÉNDEZ-TELLO ${ }^{3}$ \\ Universidad Veracruzana (México) / karoly.mendez@iberopuebla.mx
}

Recibido: 1/4/2019/ Aceptado: 13/5/2019

doi: $10.26439 /$ contratexto2019.n032.4618

Resumen. Este artículo sistematiza las experiencias de aprendizaje desarrolladas por miembros de una comunidad de práctica de análisis cinematográfico con el propósito de educar miradas para resistir la colonialidad del ver. Describe los fundamentos teóricos de la alfabetización audiovisual en clave decolonial, el proyecto político-pedagógico desde el cual se impulsó la formación de miradas; además, presenta las películas que se analizaron y los criterios que guiaron el proceso de selección. Da cuenta desde qué supuestos y de qué modo se hizo la sistematización de las experiencias por el facilitador y los aprendices del curso Gramática del Cine Sonoro, en la Especialización en Estudios Cinematográficos (EEC) de la Universidad Veracruzana (México), un programa de posgrado con participantes provenientes de disciplinas académicas diversas. Al presentar evidencia empírica de las voces y miradas de los aprendices, describe una experiencia educativa innovadora por el perfil diverso de los aprendices, por el marco académico, institucional y nacional en el que tuvo lugar y por integrar perspectivas críticas de los estudios cinematográficos, los estudios visuales, la educación para los medios y la educación orientada a construir interculturalidad y decolonialidad.

Palabras clave: alfabetización mediática decolonial / estudios cinematográficos / educación antirracista / representación / otredad

\footnotetext{
1 Doctor en Investigación Educativa por la Universidad Veracruzana, México y Estudios Avanzados en Historia del Cine por la Universidad Autónoma de Madrid, España. https://www.orcid.org/0000-0002-3900-5250

2 Maestra en Comunicación Social por la Pontificia Universidad Católica de Chile https://orcid.org/00000002-8110-1094

3 Maestranda en Comunicación y Cambio Social por la Universidad Iberoamericana, México. https://orcid. org/0000-0001-6197-7059
} 


\section{EDUCATING GAZES THAT OFFER RESISTANCE TO THE COLONIALITY OF SEEING}

Abstract: This article systematizes the learning experiences developed by members of a film analysis community of practice whose purpose was to educate gazes to offer resistance to the coloniality of seeing. It describes the theoretical foundations of decolonial audiovisual literacy, and the political-pedagogical project from which the education process was promoted. In addition, it presents the films that were analyzed and the criteria that guided the selection process. It explains from which assumptions and in which way the systematization of experiences was carried out by facilitators and apprentices participating in the Sound Film Grammar subject of the Specialization in Film Studies (EEC) of the University of Veracruz (Mexico): a graduate program where apprentices from diverse academic disciplines participate. By presenting empirical evidence of the apprentices' voices and gazes, it describes an innovative educational experience due to the diverse profile of the apprentices; the academic, institutional and national framework in which it took place; and the integration of critical perspectives of film studies, visual studies, media education and education aimed at building interculturality and decoloniality.

Keywords: Decolonial media literacy / film studies / anti-racist education / representation / otherness

\section{EDUCAR OLHARES EM RESISTÊNCIA À COLONIALIDADE DE VER}

Resumo. Este artigo sistematiza as experiências de aprendizagem desenvolvidas por integrantes de uma comunidade na prática de análise de filmes que teve como objetivo educar os olhares para resistir a colonialidade de ver. Descrevem-se os fundamentos teóricos da alfabetização audiovisual em chave decolonial, projeto político-pedagógico a partir do qual se impulsiona a formação de olhares. Além disso, apresenta os filmes que foram analisados e os critérios que orientaram o processo de seleção. Apresenta quais os pressupostos e qual a forma como se conduziu a sistematização das experiências por parte do professor e alunos do curso de Gramática na Especialização em Estudos Cinematográficos (EEC) da Universidade Veracruzana (México); um programa de pós-graduação onde participam aprendizes de diversas disciplinas acadêmicas. Ao se apresentar as evidências empíricas das vozes e olhares dos aprendizes, descreve-se uma experiência educacional inovadora pela confluência de perfis diversificados dos estudantes, pelo contexto académico, institucional e nacional em que ela aconteceu e integrando perspectivas críticas de estudos cinematográficos, estudos visuais, a educação para a mídia e educação voltada à construção da interculturalidade e da descolonialidade.

Palavras-chave: Alfabetização midiática decolonial / estudos de cinema / educação antirracista / representação / alteridade 


\section{RESISTENCIA PEDAGÓGICA A LA DOMINACIÓN SIMBÓLICA DE CUÑO COLONIAL}

El presente artículo es nuestra palabra sobre el proceso de alfabetización audiovisual en el que participamos, situada en nuestro particular punto de mira y escucha como aprendices y facilitadores. Construimos nuestras reflexiones partiendo de reconocer que el cine, la televisión y el video bajo demanda dominante, en tanto productos culturales creados desde el poder, reproducen sistemas de pensamiento orientados a legitimar relaciones sociales de dominación. La producción audiovisual que difunden los grandes consorcios de medios de comunicación reproduce miradas de lo propio y lo otro desde ideologías de dominación como la colonialidad (Quijano, 2000), el racismo (Grosfoguel, 2012) y el patriarcado (Bidaseca y Vázquez Laba, 2011). De tal suerte que, reproduce desigualdades en el acceso al reconocimiento social de sujetos y colectivos diversos; con fundamento en sus características físicas, culturales, identitarias, origen étnico o geográfico, lengua o religión, condición social o económica, o en combinaciones de todas ellas.

Entendemos que la representación de civilizaciones, culturas e identidades diversas es un campo de lucha donde se enfrentan grupos sociales con cuotas desiguales de poder, así como cosmovisiones y objetivos políticos radicalmente distintos, y que la pedagogía del poder (Möller, 2002) moldea gran parte del contenido que circula ampliamente en medios de comunicación como el cine, la televisión y el video bajo demanda. De tal suerte que, con el propósito de asegurar "el control geopolítico de la alteridad a nivel global" (León, 2012 p. 118), desde los centros globales del poder económico y político se impulsa la creación y distribución masiva de contenidos.

Al mismo tiempo, en México como en el resto de América Latina, la visualidad hegemónica reproduce la colonialidad del ver (Barriendos, 2011), un sistema de construcción simbólica que desde la perspectiva del poder "moderno-colonial" opera como parámetro para racializar, inferiorizar y occidentalizar a sujetos y grupos extraeuropeos. Al reconocer que las "prácticas del ver" dominantes producen imaginarios que tienen un impacto político decisivo en los procesos de reconocimiento identitario de sujetos y grupos (Brea, 2005, p. 9), es decir, que en mayor o menor medida el consumo audiovisual que realizan incide en sus procesos de construcción identitaria (Morduchowicz, 2008), consideramos menester dotar a los sujetos de herramientas teórico-metodológicas que les permitan resistir esa dominación simbólica.

Con ese propósito, el proceso de alfabetización audiovisual en el que participamos, la implementación del curso Gramática del Cine Sonoro, de la Especialización en Estudios Cinematográficos (EEC) ${ }^{4}$ de la Universidad Veracruzana (México), se orientó

4 En el 2018, de la primera generación que cursó el posgrado egresaron 13 especialistas, provenientes de 9 licenciaturas distintas, todos originarios de diferentes lugares de Veracruz, México. Licenciados en Animación, Antropología Social, Ciencias de la Comunicación, Derecho, Diseño 
a educar miradas (Dussel, 2006), es decir, a potenciar la capacidad de los sujetos para problematizar lo que ven, comprender cómo se construyen sentidos articulando los componentes del lenguaje cinematográfico y cuestionar lo que dan por sentado las narrativas audiovisuales. En definitiva, se orientó a formar miradas en resistencia a la colonialidad del ver (Barriendos, 2011) para hacer lecturas críticas e identificar estrategias narrativas empleadas para visibilizar o invisibilizar sujetos, grupos, objetos, ideas y perspectivas, o bien para construir representaciones estereotípicas fundamentadas en ideologías de dominación.

En las páginas siguientes, Angélica y Károly, posicionadas como aprendices, y Rodrigo, posicionado como facilitador, daremos cuenta de las lecciones aprendidas sistematizando nuestra experiencia (Barnechea y Morgan, 2010). En primer lugar, las lecciones aprendidas sobre el lugar de nuestro proyecto político-pedagógico dentro de los estudios cinematográficos, los estudios visuales y las pedagogías críticas. Luego, nuestras reflexiones acerca de la selección de películas empleadas como objeto de análisis y de la metodología empleada tanto para implementar el curso como para sistematizar nuestra experiencia. Finalmente, describiremos las lecciones aprendidas sobre el potencial que ofrece nuestra propuesta para construir miradas en clave decolonial en procesos de alfabetización audiovisual.

\section{FUNDAMENTOS PARA UNA ALFABETIZACIÓN AUDIOVISUAL EN CLAVE DECOLONIAL}

Al articular nuestras ideas para redactar este texto, ocho meses después de haber concluido la implementación del curso, reconocemos que nuestro proyecto de educar miradas en resistencia a la colonialidad del ver (Barriendos, 2011) se fundamenta en una amalgama de conceptos generados desde los estudios cinematográficos, los estudios visuales, la educación para los medios y la educación orientada a construir interculturalidad y decolonialidad. En primer lugar, con respecto a los estudios cinematográficos, consideramos pertinente señalar que, en mayor o menor medida desde su origen en la primera mitad del siglo XX, la enseñanza cinematográfica en el mundo ha implicado formar las miradas de los aprendices, alfabetizarlos en el uso del lenguaje cinematográfico como instrumento de comunicación.

Inicialmente los proyectos formativos contemplaban la formación de miradas de modo instrumental en relación con su objetivo primordial: formar cineastas, es decir, profesionales capaces de crear visiones cinematográficas del mundo. Y con ese propósito, en 1920 se fundó en Moscú el Instituto Estatal de Cinematografía; en 1929, la

Gráfico, Fotografía, Gestión Intercultural para el Desarrollo, Ingeniería Ambiental, Publicidad y Relaciones Públicas, y Teatro. 
Universidad del Sur de California ofreció el primer programa universitario de cine en Estados Unidos; en 1935, se fundó en Roma el Centro Experimental de Cinematografía; en 1947, se fundaron la Escuela de Teatro, Cine y Televisión de la Universidad de California en Los Ángeles y el Instituto de Investigaciones y Experiencias Cinematográficas, luego Escuela Oficial de Cine, en Madrid; y en 1948, se fundó en Polonia la Escuela de Cine de Lodz, centros de estudios donde cineastas de reconocido prestigio internacional se formaron o han dado cátedra.

Dentro de esa corriente, en México se fundaron en 1963 y 1975, respectivamente, el Centro Universitario de Estudios Cinematográficos (CUEC) de la Universidad Nacional Autónoma de México (UNAM), la escuela de cine más antigua de América Latina (López Monroy, 2006, p. 12), y el Centro de Capacitación Cinematográfica (CCC) de la Secretaría de Cultura (México), alma mater de cineastas mexicanos de reconocido prestigio internacional. Al mismo tiempo, en los años sesenta, al igual que sucedía en otras partes del mundo, en las universidades mexicanas se desarrollaron los primeros proyectos de investigación sobre cine y el Fondo de Cultura Económica publicó la revista Otrocine, la primera con artículos de investigación sobre cine (Zavala, 2017, p. 53). Se trataba principalmente de estudios con perspectiva sociológica e historiográfica. Como temas dominantes prevalecían los orígenes del cine en México, la historia del cine regional y la vida de las grandes estrellas en la época de oro (p. 55).

Y en el siglo XXI, los estudios sobre cine han diversificado sus perspectivas teóricometodológicas; se han desarrollado desde "aproximaciones humanísticas, en particular en disciplinas como filosofía, ética, estética, narratología y semiótica" (Zavala, 2017, p. 57). Programas de grado y posgrado en Historia del Arte, Filosofía, Diseño Gráfico, Artes Visuales, Literatura Comparada y Comunicación Social ofrecen de modo recurrente cursos y seminarios dedicados al estudio del lenguaje cinematográfico; y el cine es empleado como apoyo pedagógico de licenciaturas en Derecho, Arquitectura, Sociología, Idiomas y Literatura, entre muchas otras (Zavala, 2017, p. 57). Ahora, dentro de esa corriente diversificadora nosotros ponemos foco en la formación cinematográfica desde la perspectiva de la investigación educativa; reflexionando en torno a un proyecto político-pedagógico orientado a formar miradas en clave decolonial, miradas en resistencia a la colonialidad del ver (Barriendos, 2011).

Al respecto, es pertinente empezar por señalar que el plan de estudios de la Especialización en Estudios Cinematográficos (EEC) parte de un posicionamiento político-pedagógico que reconoce la necesidad de ampliar el significado del concepto "alfabetización", para que implique saber leer y escribir textos en la multiplicidad de lenguajes y soportes que actualmente se utilizan para producir y compartir información, y no solo textos impresos (Fueyo, 2003). Entiende que "saber leer" supone leer cuestionando las relaciones de poder que reproducen los discursos y que la formación básica de 
todo individuo debe permitirle comprender las funciones de los medios de comunicación, evaluar sus contenidos y tomar decisiones fundadas como consumidor y creador. Por ello, tiene como propósito facilitar que, independientemente de la disciplina académica de la que provengan y de su trayectoria profesional, los aprendices encuentren condiciones favorables para desarrollar su capacidad de analizar el modo en que los medios audiovisuales construyen sentido y emplearlos como herramientas de comunicación.

Está estructurado en dos periodos semestrales con ocho experiencias educativas cada uno, ocho asignaturas organizadas en torno a dos líneas de generación y aplicación del conocimiento (LGAC): estudios cinematográficos y escritura creativa de la reseña cinematográfica. El primer semestre incluye Gramática del Cine Silente y Gramática del Cine Sonoro (asignaturas con énfasis teórico); Crítica Cinematográfica y Taller Inicial de Reseña Crítica (con énfasis en la escritura); y Estructura Dramática, Construcción de Personajes, División del Trabajo en el Cine, y Producción y Distribución de Ficción (con énfasis en la creación audiovisual).

El segundo incluye Géneros Cinematográficos y Análisis Semiótico del Cine (con énfasis teórico); Taller Avanzado de Reseña Crítica (con énfasis en la escritura); y Producción y Distribución de Documental, Taller de Guion, Taller de Producción, Taller de Realización y Taller de Montaje y Posproducción (con énfasis en la creación audiovisual). Gramática del Cine Sonoro es la experiencia educativa que ha servido de laboratorio para articular e implementar conceptos generados desde los estudios cinematográficos, los estudios visuales, la educación para los medios y la educación orientada a construir interculturalidad y decolonialidad en la formación de miradas críticas.

Desde la perspectiva de los estudios visuales, la alfabetización audiovisual que proponemos reconoce que los "actos de ver" son prácticas complejas de construcción cultural que resultan de la articulación de un espeso entramado de "operadores" textuales, mentales, imaginarios, sensoriales, mnemónicos, mediáticos, técnicos, burocráticos, institucionales, y de "intereses de representación" de raza, género, clase, diferencia cultural, grupos de creencias u otras afinidades (Brea, 2005, p. 8-9). Por lo tanto, el análisis de obras resultado de esos "actos de ver" puede visibilizar los procesos de construcción de diferenciaciones sociales, de género, clase social, raciales y étnicas de los que forman parte (Torricella, 2018, p. 44), de tal suerte que también sea posible y deseable discutir en qué medida las representaciones de la diversidad hacen justicia o no a las identidades y culturas, sujetos o grupos que buscan representar (Dussel, 2006).

Desde la perspectiva pedagógica, se enmarca, por una parte, en lo que Barbas Coslado (2012, p. 163) llama la tradición "dialógica" y Hobbs (2011, p. 422) "empoderadora" de la educación para los medios, enfocada en promover la construcción y deconstrucción colectiva de mensajes con un fuerte componente político de transformación social, es decir, en impulsar el desarrollo de conocimientos y habilidades que 
fortalezcan las capacidades ciudadanas de análisis crítico de información. Entendemos que todo proceso de alfabetización audiovisual debe facilitar "el cuestionamiento crítico de la cultura de los medios de comunicación y de las industrias culturales desde múltiples perspectivas, abordando cuestiones de clase, raza, género, sexualidad y poder" (Kellner y Share, 2007, p. 9, traducción propia), si se propone contribuir a la construcción del bien común desde una perspectiva radical.

Por otra, se enmarca en la tradición "crítica" de la educación orientada a construir interculturalidad y decolonialidad, la cual dirige su acción educativa no solo hacia sujetos de grupos sociales dominados, sino principalmente hacia miembros de los grupos dominantes, y tiene como propósito construir relaciones horizontales entre identidades y culturas diversas (López Hurtado, 2009). Por ello, apostamos por una praxis pedagógica crítica que, partiendo de reconocer las desigualdades en el acceso a la justicia como reconocimiento social, participación política y acceso a recursos materiales que experimentan sujetos y grupos, contribuya a deconstruir y derruir los sistemas simbólicos de dominación que las producen y a construir imaginarios plurales e igualitarios donde quepan y sean valoradas positivamente manifestaciones culturales, identitarias y políticas de origen diverso.

En particular, buscando articular la pedagogía en clave decolonial (Díaz, 2010) y la alfabetización mediática decolonial (Zárate-Moedano, 2018), su diseño e implementación tuvo como propósito visibilizar, deconstruir y contrastar la pedagogía del poder (Möller, 2002) de cines hegemónicos con formas Otras de imaginar y construir el mundo, así como visibilizar y cuestionar el acceso desigual al reconocimiento social de civilizaciones, culturas e identidades diversas en los cines dominantes. Para ello, adoptó una comprensión crítica de la historia del cine, buscó descentrar y relativizar el punto de vista hegemónico, desestabilizar y debilitar la visión eurocéntrica-occidental, al mismo tiempo que reconoció formas diversas de ver, comprender y construir la realidad y la fantasía cinematográfica, y recuperó narrativas de quienes son y han sido objeto de dominación colonial.

El propósito fue detonar "reflexiones y acciones críticas encaminadas a resistir y deshabilitar el entramado conceptual y operativo de la perspectiva hegemónica colonial" (Díaz, 2010, p. 231), en particular, capacitar a los sujetos para identificar cómo se construyen privilegios y desventajas en la representación de la diversidad y cómo contribuye esa producción cultural "a construir la realidad, racializando procesos de opresión y exclusión" (Zárate-Moedano, 2018, p. 319). Respecto a la perspectiva decolonial que adoptamos, consideramos pertinente señalar que asumimos la necesidad de reconocer los límites del pensamiento decolonial predominante y el peso del género en las estructuras de poder. Por ello buscamos pensar la raza intersecada por el género e incorporamos las perspectivas de mujeres indígenas del sur, sus voces y miradas sobre las luchas que enfrentan en sus trayectorias de vida (Bidaseca y Vázquez Laba, 2011, p. 24). 
De esta manera buscamos que el proceso de enseñanza cinematográfica desarrollado en el curso Gramática del Cine Sonoro operara como laboratorio para construir una propuesta de alfabetización audiovisual en clave decolonial, para detonar "actos de ver" que sean contrapeso a discursos que reproducen ideologías de dominación (Shohat y Stam, 2002, p. 190). Nos propusimos crear un espacio de reflexión acerca de qué miramos y cómo miramos para combatir la selectividad de escucha y visualidad promovida desde el poder, aumentar el nivel de concienciación de todas las voces culturales existentes y contribuir a "remediar la falta de experiencias de alterización entre los estudiantes más privilegiados, ayudándoles a imaginar posturas alternativas en las que un sujeto puede situarse y deseos sociales distintos de los suyos" (Shohat y Stam, 2002, p. 327). En suma, buscamos crear condiciones favorables para visibilizar y deconstruir la perspectiva eurocéntrica que estructura las narraciones hegemónicas, visibilizar cómo reproducen y normalizan una perspectiva colonial de las relaciones sociales, cómo excluyen voces, miradas, ideas y estéticas dominadas, por ejemplo, cómo exaltan "lo europeo" y menosprecian "lo indígena".

\section{UNA MUESTRA CINEMATOGRÁFICA PARA VISIBILIZAR LA COLONIALIDAD DEL VER}

Un componente fundamental del proceso de alfabetización audiovisual en clave decolonial que proponemos es la muestra de textos audiovisuales y escritos que habrán de ser analizados, es decir, la materia prima para detonar procesos de reflexión y diálogo en el aula y más allá de sus fronteras. Por ello, buscando educar miradas en resistencia a la colonialidad del ver (Barriendos, 2011) la selección de materiales fue realizada con base en los fundamentos teóricos descritos en el apartado anterior. Y en particular con la muestra cinematográfica elegida, se apostó por desestabilizar y debilitar la visión eurocéntrica-occidental de qué merece ser visto, es decir, por descentrar y relativizar el punto de vista hegemónico de la historia del cine.

La selección de películas ofrecida como objeto de análisis en el curso Gramática del Cine Sonoro buscó abarcar la más amplia variedad de visiones del mundo a lo largo de ocho décadas, desde mediados de los años 30 del siglo xx, cuando el cine de sonido sincrónico se había consolidado industrialmente, hasta ochenta años después, 2015, en la era Netflix. Se hizo hincapié en visibilizar formas diversas de ver, comprender y construir el mundo por medio del cine; y en especial, recuperar perspectivas o narrativas de quienes son y han sido objeto de dominación colonial. Por ello incluyó visiones de hombres y de mujeres, de pueblos originarios, mestizos y criollos, así como de colectivos dominadores y colectivos en resistencia dentro de espacios geográficos y culturales diversos. Todo ello, con el propósito de 1) visibilizar cómo se articulan los componentes del lenguaje cinematográfico para construir sentido desde posicionamientos políticos diversos, 2) visibilizar su calidad de constructo, 3) facilitar el contraste de representaciones distintas 
sobre un mismo tema o temas similares, 4) visibilizar desigualdades en el acceso al reconocimiento social de identidades y culturas diversas, así como 5) nombrar y cuestionar las ideologías de dominación que las legitiman.

Es importante señalar que el calendario universitario y el programa del curso impusieron un límite de 15 sesiones de trabajo, por ello la muestra incluyó 15 películas de largometraje (de ficción y documentales). Para elegirlas, aparte de los criterios mencionados líneas arriba, se consideró qué tan fácil o difícil resultaba conseguirlas. Además, tratamos de elegir películas de fácil acceso en línea o en nuestra ubicación geográfica. Las películas fueron agrupadas en tres bloques temáticos tratando de que cada uno aportara elementos para analizar relaciones de poder con respecto a la raza, la clase o el género de los sujetos y grupos representados. Se denominaron: 1) Ideología y Abuso de Poder, 2) Los Indígenas Cinematográficos y 3) Mujeres que Luchan.

El primer bloque, integrado por El triunfo de la voluntad (1935, Alemania) de Leni Riefenstahl, El gran dictador (1940, Estados Unidos) de Charles Chaplin, La batalla de Argel (1966, Italia-Argelia) de Gillo Pontecorvo, Apocalypse Now (1979, Estados Unidos) de Francis Ford Coppola y Rojo amanecer (1989, México) de Jorge Fons. Cinco películas que han enfrentado algún tipo de censura porque han incomodado al poder y son solo una mínima muestra de todas las películas que han sido censuradas en la historia del cine mundial, en todos los continentes.

El segundo, integrado por María Candelaria (1943, México) de Emilio Fernández, Tonta, tonta pero no tanto (1972, México) de Fernando Cortés, Los herederos (2008, México) de Eugenio Polgovsky, La hija de la laguna (2015, Perú) de Ernesto Cabellos y También la lluvia (2010, España) de Icíar Bollaín. Cinco películas que ofrecen miradas desde arriba y desde abajo hacia los pueblos originarios; narrativas originadas a mediados y finales del siglo $x x y$ al inicio del siglo $x x I$ que reproducen imaginarios racistas desde el poder o bien se posicionan al lado de los pueblos originarios y sus luchas contra poderes coloniales.

Y el tercero, integrado por Te doy mis ojos (2003, España) de Icíar Bollaín, Cicatrices (2005, México) de Francisco del Toro, Madeinusa (2006, Perú) de Claudia Llosa, Princesas (2005, España) de Fernando León de Aranoa, y La bicicleta verde (2012, Arabia Saudí) de Haifaa Al-Mansour. Cinco películas que representan la violencia machista que sufren mujeres en España, México, Perú y Arabia Saudí, que permiten contrastar dicho fenómeno desde miradas machistas y feministas, desde la perspectiva de hombres y mujeres.

Ahora bien, el propósito del primer bloque, Ideología y Abuso de Poder, fue hacer evidente que toda narración cinematográfica se construye desde un posicionamiento político particular y que las formas en que se articulan los elementos del lenguaje cinematográfico construyen sentidos determinados. Por ello, contrastó dos formas radicalmente distintas de representar al dictador Hitler, una a favor y otra en contra, dos discursos políticos divergentes. También contrastó dos formas radicalmente distintas 
de representar procesos de descolonización en África y Asia, desde la perspectiva del poder colonizador y desde la del pueblo en resistencia. Contrastó dos formas distintas de representar la diversidad y, en particular, la otredad, desde una perspectiva humanista y plural, y desde una perspectiva racista monocultural. Y cerró, con una muestra de cine independiente mexicano que, desde la perspectiva del pueblo en resistencia, denuncia la brutalidad del Estado, denuncia el abuso de poder ejercido con violencia en contra de adversarios políticos en el interior de la nación.

El propósito del segundo bloque, Los Indígenas Cinematográficos, fue visibilizar la lucha cotidiana de los pueblos originarios por existir; resistiendo la dominación colonial, simbólica y material. Para ello, contrastó dos representaciones arquetípicas de la industria audiovisual mexicana, dos discursos racistas y coloniales sobre la mujer indígena, con dos historias contadas a partir del reconocimiento social igualitario en la diversidad, dos representaciones de pueblos originarios como dueños de su destino. Para finalmente, reflexionar sobre cómo se construyen conquistadores y conquistados, el presente y el pasado, quiénes dominan y quiénes son dominados; y contrastarlo con dos narraciones documentales de cortometraje, Hamac Caziim (2007, México) de Jerónimo Barriga y Existe cuando hablas (2015, México) de José Santiago Francisco y Rodrigo Zárate Moedano, que dan cuenta de la resistencia simbólica y material de los pueblos originarios comcaac $y$ totonaco (México) ante el poder colonial en el presente.

El propósito del tercer bloque, Mujeres que Luchan, fue poner foco en algunas de las problemáticas vinculadas con la violencia machista que enfrentan mujeres diversas en contextos geográficos y culturales diversos, destacando sus formas de hacerle frente, de luchar y resistir. Contrasta dos relatos sobre mujeres violentadas por sus maridos, uno que cuestiona el injusto orden de las cosas desde el feminismo y otro que pretende cuestionarlo, pero termina legitimándolo desde una visión católica machista. Visibiliza la violencia sexual de un padre a sus hijas en los Andes peruanos, las violencias que enfrentan dos prostitutas en Madrid, España, y la violencia sutil de que es objeto una niña en Arabia Saudí que demanda un trato igualitario con respecto a los niños.

Sin duda, la muestra es perfectible, puede llegar a ser más plural, a representar una mayor diversidad de cinematografías, perspectivas, identidades y culturas, pero, como argumentaremos páginas adelante al describir los aprendizajes construidos con la implementación del curso, a pesar de sus limitaciones, permite visibilizar, deconstruir y contrastar la pedagogía del poder (Möller, 2002) de cines hegemónicos con formas distintas de contar el mundo, "poner en crisis" la visión eurocéntrica-occidental acerca de qué merece ser visto según las historias del cine tradicionales, visibilizar y cuestionar el acceso desigual al reconocimiento social de civilizaciones, culturas e identidades diversas en los cines dominantes y acercar a los aprendices a "cines" y cineastas que valoran positivamente manifestaciones culturales, identitarias y políticas de origen diverso. 


\section{CÓMO SISTEMATIZAMOS NUESTRAS EXPERIENCIAS EN UNA COMUNIDAD DE PRÁCTICA}

Al inicio de este artículo hicimos explícito que recoge "nuestra palabra situada" sobre el proceso de alfabetización audiovisual en el que participamos, porque asumimos que no hay proceso de construcción de conocimientos que no tenga lugar arraigado en un particular momento histórico-social y se desarrolle desde un lugar de enunciación concreto. Por ello, consideramos pertinente describir el proceso de investigación empezando por visibilizar nuestro locus de enunciación, nuestro particular punto de partida intelectual y experiencial. En primer lugar, emprendimos el proyecto de educar miradas para resistir la colonialidad del ver (Barriendos, 2011) reivindicando el reconocimiento social igualitario de las identidades y culturas originarias con respecto a las identidades y culturas dominantes en México, las de la población mestiza.

Además, desarrollamos nuestra acción político-pedagógica posicionados del lado de la resistencia indígena frente al poder colonial. Por una parte, Angélica y Károly, aprendices en la comunidad de práctica (Wenger, 2001), originarias de dos diferentes comunidades de la Sierra de Zongolica e identificadas como nahuas, pueblo originario de ese territorio. Por otra, Rodrigo, facilitador en la comunidad de práctica, que se reivindica como víctima del etnocidio perpetrado por el Estado mexicano posrevolucionario (Bonfil Batalla, 2010); debido a que hace cuatro generaciones su familia se "desindianizó" dejando de reproducir el maya como primera lengua y su bisabuela, parte de la primera generación en no hablar maya, trabajó como maestra rural castellanizadora una vez concluida la revolución mexicana.

Ahora bien, cuando describimos los fundamentos de la alfabetización audiovisual en clave decolonial que proponemos, avanzamos pistas acerca de la comunidad académica desde la cual abordamos la sistematización de nuestra experiencia. En ese sentido, consideramos relevante señalar que existimos, pensamos y escribimos desde una de las universidades públicas de mayor tradición, prestigio y matrícula del sureste mexicano; y nuestras trayectorias académicas tienen como punto de encuentro disciplinar la comunicación, en particular la comunicación audiovisual. También es relevante que tanto Angélica como Rodrigo han desarrollado su formación y su práctica docente en sintonía con el enfoque intercultural crítico asumido por la Universidad Veracruzana Intercultural y el Instituto de Investigaciones en Educación.

Angélica es licenciada en Gestión Intercultural para el Desarrollo con orientación en Comunicación por la Universidad Veracruzana Intercultural (México), maestra en Comunicación Social con mención en Comunicación y Educación por la Pontificia Universidad Católica de Chile, ha participado en cursos y talleres de cine comunitario e investigación con perspectiva de género y es responsable del Laboratorio Multimedia de la Universidad Veracruzana Intercultural en su sede Grandes Montañas de la Sierra de Zongolica. Károly es comunicóloga por la Universidad Veracruzana (México), ha participado en cursos y talleres de producción audiovisual, fotoperiodismo, radio y 
comunicación indígena, y realizó una estancia de Movilidad Internacional en el Programa de Cine y Audiovisuales de la Universidad del Magdalena (Colombia).

Rodrigo es comunicólogo por la Universidad de Xalapa (México), diplomado en Estudios Avanzados en Historia del Cine por la Universidad Autónoma de Madrid (España), maestro en Tecnología Educativa por la Universidad Da Vinci (México) y doctor en Investigación Educativa dentro de la línea de Educación Intercultural por la Universidad Veracruzana (México). Ha trabajado como realizador de documentales de divulgación científica, ha impartido cursos y talleres de creación y análisis audiovisual en el ámbito universitario, coordina la Especialización en Estudios Cinematográficos. Su tesis doctoral se titula: "Hacia una educación intercultural para los medios: alfabetización mediática para visibilizar la reproducción del racismo y reconocer identidades originarias y afrodescendientes en el Campus Xalapa de la Universidad Veracruzana".

De esa manera, desde nuestros respectivos puntos de partida intelectual y experiencial, sistematizamos nuestras experiencias de aprendizaje (Barnechea y Morgan, 2010) en primer lugar por separado. Cada uno hizo un ejercicio individual de memoria y reflexión que supuso el insumo inicial del proceso de memoria y reflexión colectiva; que, por medio del trabajo colaborativo, del diálogo y la reflexión, nos llevó a articular un discurso común como miembros de la comunidad de práctica. Así, ocho meses después de haber concluido las actividades de aprendizaje del curso, facilitador y aprendices recapitulamos y evaluamos el trabajo realizado, con el fin último de construir conocimientos que faciliten perfeccionar el plan de estudios y su implementación. Reflexionamos acerca de los procesos de enseñanza-aprendizaje desarrollados en cada una de las 15 sesiones de trabajo del curso; en particular acerca del modo en que aprendimos a contextualizar y deconstruir narrativas audiovisuales, de cómo facilitó la construcción de capacidades críticas y creativas en torno a la representación de identidades.

Para enriquecer nuestra visión de los hechos, solicitamos por escrito a los otros once aprendices de la comunidad de práctica que respondieran cinco preguntas: ¿Qué fue lo que más te gustó o no te gustó del contenido y la dinámica del curso Gramática del Cine Sonoro? ¿Qué aprendizajes te dejó tu participación en el primer bloque, Ideología y Abuso de Poder, y qué película del bloque te resultó de mayor interés, más significativa en el debate de clase? ¿Qué aprendizajes te dejó tu participación en el segundo bloque, Los Indígenas Cinematográficos, y qué película del bloque te resultó de mayor interés, más significativa en el debate de clase? ¿Qué aprendizajes te dejó tu participación en el tercer bloque, Mujeres que Luchan, y qué película del bloque te resultó de mayor interés, más significativa en el debate de clase? ¿Has aplicado o aplicas esos aprendizajes fuera del aula, fuera del curso, en qué contexto, de qué manera? ${ }^{5}$

5 El medio de comunicación empleado fue el sistema de Mensajes Privados de Facebook. En las páginas siguientes, los testimonios de los aprendices generados de esta manera serán identificados de este modo: nombre del estudiante, comunicación personal, fecha. 
A dicha solicitud respondieron únicamente cinco aprendices. Contrastamos nuestras perspectivas con las suyas y desarrollamos un proceso de innovación curricular (Domínguez, Medina y Sánchez, 2011) que consistió en reconstruir nuestra experiencia en la comunidad de práctica con una perspectiva crítica, orientada a identificar cómo perfeccionar el proyecto formativo que dotó de contenido y definió la práctica del proceso de enseñanza-aprendizaje, asumiendo que los procesos de innovación deben valorar la pertinencia del programa educativo en el marco de la sociedad del conocimiento y los retos interculturales que presenta, y demostrar que los implicados en los procesos logran los objetivos y dominan las competencias básicas que se estiman más valiosas.

La comunidad de práctica operó como espacio, método y objeto de investigación, y nosotros, como autores de este texto, buscamos dar cuenta del proceso de innovación curricular (Domínguez, Medina y Sánchez, 2011) impulsado, respondiendo ¿en qué medida el curso logró visibilizar desigualdades en el acceso a la justicia social como reconocimiento de culturas e identidades diversas? ¿En qué medida se transformaron sus patrones de pensamiento cursando la experiencia educativa? ¿En qué medida fue pertinente el contenido y las prácticas del curso en el marco de la sociedad del conocimiento y los retos interculturales que presenta?

\section{APRENDIZAJES DE UNA COMUNIDAD DE PRÁCTICA DE ANÁLISIS CINEMATOGRÁFICO}

En relación con la selección de películas y su propósito de descentrar y relativizar el punto de vista de las historias del cine hegemónicas, acercar a los estudiantes a una mayor pluralidad de narrativas y formar miradas críticas, es significativo que para Sara (Ingeniería Ambiental) ${ }^{6}$, el curso fue útil para "conocer obras que no habría tomado en consideración" por sí misma; le facilitó que ampliara su interés en acceder a una mayor pluralidad cinematográfica (Sara, comunicación personal, 22 de abril del 2019). Silvia (Teatro) considera que analizar películas que ya había visto como El gran dictador y Apocalypse Now "fue de gran aporte [...] pues no es lo mismo verlas solo por verlas a hacerlo con detalle y lista para analizarlas" (Silvia, comunicación personal, 22 de abril del 2019). René (Gestión Intercultural para el Desarrollo) asume que observar detalles antes inadvertidos hacen que "la experiencia de ver una película no vuelva a ser la misma" (René, comunicación personal, 22 de abril del 2019).

En primer lugar, las sesiones de trabajo del bloque Ideología y Abuso de Poder, con las primeras cinco películas, sirvieron para presentar las herramientas conceptuales y metodológicas del curso, para establecer, en términos generales, la perspectiva de

6 A partir de este punto y con el propósito de contextualizar los testimonios, el nombre de los aprendices irá acompañado del nombre del programa de licenciatura del que egresaron. 
análisis cinematográfico propuesta. De tal suerte que el contraste de El triunfo de la voluntad y El gran dictador, y de La batalla de Argel y Apocalypse Now, es decir, el contraste de narrativas radicalmente distintas por su punto de vista acerca de los mismos personajes y hechos, o similares, hizo evidente que el cine es un instrumento de comunicación, una herramienta de propaganda, un vehículo de ideologías, en palabras de René (Gestión Intercultural para el Desarrollo):

...sirvió para reconocer que la historia la hace quien la cuenta y que el cine es un medio de comunicación poderoso para transmitir ideas [...] decidir lo que se informa y lo que no, lo que se ve y lo que no... son facultades que tienen los realizadores cinematográficos. Por tanto, en el cine podemos tener más de una versión de una historia y de sus personajes, la cual a veces puede ser contrapuesta. Un tirano puede ser elevado a la categoría de mesías y viceversa, como pasa en El triunfo de la voluntad y El gran dictador. Una intervención militar puede ser contada desde el punto de vista del que oprime o del oprimido, validando o reprobando la invasión, como en Apocalypse now y La batalla de Argel. (René, comunicación personal, 22 de abril del 2019)

En particular sobre la representación del Otro desde la mirada colonial de Occidente, los aprendices coincidieron en que Hollywood ha construido un "árabe cinematográfico" estereotípico vinculado con el abuso del poder, con la reproducción de ideologías de muerte como el terrorismo; y un "vietnamita" igualmente estereotípico, enemigo, violento, sin voz ni mirada propia. Además, indicaron que para cuestionar los relatos unidimensionales de Hollywood es necesario conocer una mayor cantidad y variedad de películas desde perspectivas Otras de Medio Oriente, el Lejano Oriente y África.

Por otra parte, a partir del estudio de Rojo amanecer y su contraste con las cuatro películas anteriores infirieron que los cineastas tienen la capacidad de cuestionar el abuso del poder o bien lavar la cara a regímenes que han abusado de él; y el contraste entre discursos y contradiscursos facilita visibilizar situaciones de injusticia, de abuso de poder y de violencia. También, que desde abajo se pueden construir relatos críticos del poder; y que, con un presupuesto reducido, el sonido puede contar situaciones que sería muy costoso filmar de modo realista como la masacre de Tlatelolco.

Concluyeron que los realizadores tienen la capacidad y el poder de construir emociones positivas o negativas haciendo uso del lenguaje cinematográfico, es decir, de construir discursos que muevan al aprecio o al desprecio del objeto de representación. La banda sonora articulada con la banda de imagen ofrece una amplia gama de posibilidades expresivas y narrativas para construir la realidad y moldear nuestra percepción de esta; y sea de izquierda o de derecha, desde arriba o desde abajo, el poder emplea el cine para reproducir su visión del mundo, porque nombrar el mundo es construirlo.

En las siguientes cinco sesiones, las del bloque Los Indígenas Cinematográficos, contrastaron dos películas de ficción de mirada colonial y racista, con dos películas 
documentales que reconocen la dignidad de los pueblos originarios y sus luchas. Por una parte, como resultado de analizar María Candelaria y Tonta, tonta pero no tanto, afirmaron que, desde el poder, los "indígenas cinematográficos" que construyó el cine mexicano a lo largo del siglo xx reproducen el imaginario racista promovido por la ideología mestizante del Estado mexicano; y, de forma general, esa sigue siendo la forma de construirlos en el siglo xxI. En ese sentido, René (Gestión Intercultural para el Desarrollo) destaca que "los grupos minoritarios, indígenas y mestizos de las zonas rurales y las periferias urbanas han sido estereotipados y estigmatizados por el cine, ocupando los papeles denigrantes dentro de los filmes: villanos y sirvientes, iletrados e irresponsables" (Mijangos Zúñiga, 2019, p. 5).

Particularmente, Angélica y Károly manifestaron que los personajes de María Candelaria y Tonta, tonta pero no tanto "no nos representan como nahuas". Incluso los consideran caricaturas denigrantes que atentan contra su dignidad en tanto seres humanos. Por ello, asumen esa realidad como la motivación principal para crear narrativas distintas, orientadas a fortalecer la identidad colectiva de sus comunidades, para hacer un cine "que se haga desde y hacia lo colectivo" y sirva "para sentirnos orgullosos, como yo lo estoy, del lugar que nos ve crecer" (Méndez-Tello, 2019, p. 5); es decir, reconocen en el cine una herramienta de comunicación política para promover la reproducción cultural de sus pueblos, un arma de resistencia simbólica.

Del estudio de Los herederos y La hija de la laguna concluyeron que, no es indispensable ser "indígena" para crear representaciones sobre los pueblos originarios y sus luchas desde el reconocimiento igualitario a su dignidad; que desde el privilegio de hacer una película y presentarla en circuitos internacionales de distribución es posible construir representaciones que reconozcan en igualdad a los pueblos originarios y se posicionen de su lado para denunciar la violencia colonial que enfrentan en su vida cotidiana. Además, con el realizador zapoteco Juan José García, de Ojo de Agua Comunicación (como se citó en Santana Marroquín, 2007), reivindicamos ambas películas como "cine indígena", pues reconocemos en ellas una mirada que dignifica a los pueblos originarios, un posicionamiento político que hace visible su resistencia a las acciones depredadoras del orden moderno-colonial. Y reconocemos el cine documental como un instrumento para crear experiencias resonantes de comunicación (Baca Feldman, 2015), para construir narrativas desde abajo y visibilizar realidades que suele soslayar u ocultar la mirada colonial.

Resulta significativo el testimonio de Silvia (Teatro), pues su participación en el curso, pero particularmente en el segundo bloque, la llevó a conocer realidades que le resultaban ajenas por su trayectoria de vida, a imaginar necesidades y deseos distintos de los suyos. El análisis y contraste de las películas por medio del diálogo plural le permitieron "ponerse en los zapatos" del Otro. En ese sentido, sobre su experiencia al analizar Los herederos, señala: 
viví gran parte de mi vida en el norte del país, donde mis conflictos más directos han sido con el tema chicano [...] Al principio me sentía un poco lejana a algunos temas, pero me movió mucho la manera en la que llevamos las discusiones. Me hizo sensibilizarme a una realidad que nos corresponde a todos [...] es muy fácil hacer de lado las situaciones que vive el país y hacer de cuenta que no existen, cuando en realidad nos afectan a todos [...] Definitivamente escuchar a mis compañeros, que han conocido zonas marginadas y situaciones como esta, me llevó a sentir empatía y traté de ver el documental con una mente más abierta... (Silvia, comunicación personal, 22 de abril del 2019)

Angélica y Károly consideran de particular interés La hija de la laguna, pues visibiliza la lucha de una mujer indígena en contra de una empresa extranjera representante del poder colonial extractivista. Además, toma partido por quienes suelen estar mal representados (Shohat y Stam, 2002), nos muestra la perspectiva de quien resiste el poder colonial, recupera su voz y su mirada para construir una contranarrativa a los discursos del poder sobre el valor del territorio. $Y$ en ese sentido es significativo el testimonio de René (Gestión Intercultural para el Desarrollo), cuando aboga por "deconstruir la visión colonial que se ha formado en el cine en torno a los grupos originarios" y apostar por miradas cinematográficas que escapen de los estereotipos, sean objetivas y horizontales, y contribuyan a la no discriminación (René, comunicación personal, 22 de abril del 2019).

A partir del estudio de También la lluvia y de contrastarla con las cuatro películas anteriores concluyeron que, las luchas actuales de los pueblos originarios de América son fundamentalmente iguales a las luchas que sostuvieron los pueblos originarios durante la conquista y el dominio colonial de España y Portugal. Además, constataron que, en mayor o menor medida, para la mayoría de los aprendices "no indígenas", el curso representó un primer y contundente acercamiento al análisis cinematográfico del "indígena audiovisual", deconstruyendo las miradas que los estructuran desde arriba o desde abajo. Al mismo tiempo, también es relevante señalar que, de modo general, este segundo bloque fue el más significativo para Angélica y Károly; y para ellas se volvió evidente la necesidad de asumir una postura teórico-política para deconstruir los estereotipos denigrantes que dotan de sentido la categoría "indígena" y moldean su representación audiovisual.

Es revelador que Angélica, al igual que Silvia con el primer bloque, consiguiera mirar distinto las películas que había visto más de una vez a lo largo de su vida. En particular, al analizar Tonta, tonta pero no tanto descubrió que había naturalizado algunas ideas racistas cuando la vio anteriormente. También llevó a su memoria su adolescencia, cuando en la secundaria, a ella o a alguna amiga de ella les decían en tono despectivo: "Pareces la india María" por usar huaraches ${ }^{7}$ o hablar náhuatl. Constató que la discriminación hacia

7 En México, los huaraches son unas sandalias de cuero de manufactura artesanal que suelen ser más baratas que otros tipos de calzado, por lo cual, son de uso común entre personas de escasos 
los "indígenas" es consecuencia de la reproducción de estereotipos en el cine y la televisión, que tiene lugar de forma recurrente cuando las familias de su región disfrutan de esa película y otras similares sin cuestionar la representación que hacen de la mujer "indígena". Ahora se siente satisfecha de lo que logró al participar en ese bloque, por ello considera importante hacer que sujetos diversos de su región de origen intervengan en procesos similares de alfabetización audiovisual en clave decolonial, para que sigan disfrutando de ese tipo de cine, si así lo desean, pero de forma más crítica.

Las cinco sesiones finales, las del bloque Mujeres que Luchan, fueron útiles para enfocar el análisis en la representación de la violencia machista y las mujeres que luchan contra ella; sin embargo, detonaron especialmente reflexiones acerca de quién suele contar las historias sobre mujeres. El contraste de las cinco películas hizo evidente que la historias sobre mujeres suelen construirse desde la mirada patriarcal de los hombres. Es significativo el testimonio de Emmanuel (Fotografía), para quien el curso operó como "detonante para cuestionar por qué la producción cinematográfica carece de realizadoras femeninas" (Emmanuel, comunicación personal, 22 de abril del 2019), así como el de Sara (Ingeniería Ambiental), quien asume la responsabilidad de transformar esa realidad. "Está en nuestras manos cambiar esto" (Sara, comunicación personal, 22 de abril del 2019). Ingrid (Teatro) resalta la relevancia de que haya historias de mujeres contadas por mujeres. "Sí, la mujer protagoniza temas de violencia, discriminación y amor, pero que se hable de esos temas desde la perspectiva femenina da un giro de 180 grados" (Ingrid, comunicación personal, 22 de abril del 2019).

En particular, como resultado de contrastar Te doy mis ojos y Cicatrices, una visión feminista sobre la violencia machista contra las mujeres, con una versión católica y patriarcal sobre el mismo tema, concluyeron que, una misma situación de violencia puede contarse a favor de las víctimas o en contra de ellas, reproduciendo la mirada feminista de una mujer o la mirada machista de un hombre en el modo de construir a los personajes e implementar la puesta en escena, la puesta en cámara, la puesta en serie y el diseño sonoro. De contrastar Madeinusa y Princesas llegaron a la conclusión de que, aun las buenas intenciones de la mirada feminista a la representación de violencias machistas individuales y estructurales pueden cruzarse con imaginarios racistas sobre la otredad, y que no es indispensable ser mujer para construir un relato que cuestione la violencia machista contra las mujeres y que, además, genere empatía por las víctimas. Luego de estudiar y contrastar La bicicleta verde con las cuatro películas anteriores, afirmaron que el bloque permitió visibilizar desigualdades en el acceso al reconocimiento

recursos económicos. Junto con la ropa de manta, son parte de la indumentaria tradicional de muchos pueblos indígenas. Por ello, también son parte fundamental de las representaciones estereotípicas de los sujetos "indígenas" en el cine y la televisión. 
social entre hombres y mujeres, así como las violencias sistémicas a las que son sometidas. Además, hubo reflexiones en torno a temas dolorosos y universales derivados del abuso del poder ejercido contra las mujeres en diferentes contextos y circunstancias.

El proceso de alfabetización audiovisual en clave decolonial emprendido en el curso no solo contribuyó a formar miradas en resistencia a la colonialidad del ver (Barriendos, 2011) con respecto a la capacidad de análisis crítico de lo que los sujetos consumen, sino también a que reconocieran el potencial del cine como instrumento de transformación social y su responsabilidad ciudadana para orientar sus saberes y sus prácticas a la construcción del bien común. Los testimonios de las estudiantes resultan esclarecedores de esa consciencia: "Los bloques de películas ponen en evidencia realidades injustas que suceden día con día y que como ciudadanos debemos erradicar" (René, comunicación personal, 22 de abril del 2019). “Nos hacen saber la responsabilidad que tenemos al momento de crear contenido" (Károly, comunicación personal, 22 de abril del 2019). "Gracias al curso pude adquirir sensibilidad hacia temas que anteriormente hubiera ignorado. Ahora considero importante alzar la voz, respaldar mis opiniones con argumentos y, aún más importante, buscar el bien común mediante acciones" (Sara, comunicación personal, 22 de abril del 2019).

Tanto Angélica como Károly consideran que su participación en el curso Gramática del Cine Sonoro resultó fundamental para desarrollar los ensayos de análisis cinematográfico con los cuales concluirían sus estudios en la Especialización en Estudios Cinematográficos. Angélica escribió El cine como una oportunidad para representar voces y rostros negados y Károly El cine-video indígena. Procesos paralelos de las(os) realizadoras(es): Análisis de producciones indígenas de Ojo de Agua Comunicación. También es relevante que juntas y en colaboración con otros aprendices "no indígenas" emprendieron la realización de un cortometraje documental acerca de los problemas que enfrenta una estudiante universitaria nahua al embarazarse, y que su concepción haya sido facilitada por su participación en el curso Gramática del Cine Sonoro.

\section{EDUCAR MIRADAS PARA RESISTIR LA COLONIALIDAD DEL VER: NECESARIO Y POSIBLE}

En diciembre del 2014 tuvo lugar en México el Primer Foro de Alfabetización Mediática e Informacional en Latinoamérica y el Caribe (Amilac), que reunió a 62 expertos (investigadores, profesores y representantes de diferentes organismos educativos y culturales) de 20 países de América Latina. La sesión de trabajo "Propuestas y desafíos que enfrenta México en la alfabetización mediática e informacional" dejó ver que desde el Estado mexicano se privilegiaba la inclusión de dispositivos en los procesos educativos por encima de fomentar su uso crítico, y que los esfuerzos se enfocan en los niveles de educación básica y media exclusivamente. Por otra parte, al revisar la oferta educativa 
y la investigación educativa en el ámbito universitario, podemos constatar que tampoco es una práctica común la implementación de políticas educativas de alfabetización mediática e informacional, de tal suerte que la experiencia vivida con la implementación del curso Gramática del Cine Sonoro fue innovadora por el perfil de los aprendices que participaron en la comunidad de práctica, por el marco académico e institucional en el que tuvo lugar y por integrar perspectivas críticas de los estudios cinematográficos, los estudios visuales, la educación para los medios y la educación orientadas a construir interculturalidad y decolonialidad.

Los resultados de nuestra investigación con graduados universitarios hacen evidente la carencia de una educación crítica para los medios en los niveles de formación previos y la necesidad de ofrecer una alfabetización mediática que, como propone la Declaración de México del Foro Amilac 2014, "respalde el reconocimiento del diálogo intercultural, la no discriminación y el fomento de una cultura por la paz y la inclusión democrática" (Primer Foro Amilac, 2014: 1), lo cual, en cierta medida, logró el proceso educativo que analizamos. Además, son evidencia de que las iniciativas de alfabetización mediática, al menos en México, no necesariamente surgen del poder Estado o de una administración universitaria, sino que pueden ser impulsadas desde abajo en el aula, en un curso, por los docentes, aunque también por comunidades estudiantiles o colectivos de la sociedad civil en contextos diversos.

Consideramos necesario enfatizar que la alfabetización audiovisual en clave decolonial que intentamos describir en este artículo es 'un proyecto en construcción' un camino que debemos andar y perfeccionar repitiendo la experiencia en contextos históricosociales diversos, con aprendices y facilitadores igualmente diversos con respecto a sus identidades, culturas y trayectorias de vida. El nuestro es solo un modesto esfuerzo de resistencia que reconoce los límites que impone construir conocimientos "decoloniales" en el rígido marco de la formación universitaria de posgrado tradicional. Sin duda no alcanza para erradicar la dominación simbólica de cuño colonial que se reproduce de modo sistémico desde todas las instituciones del poder en nuestro contexto inmediato; pero sí ofrece pistas de qué estrategias político-pedagógicas podemos emplear y perfeccionar para formar miradas críticas y curiosas que cuestionen lo que damos por sentado.

Por otra parte, entender la producción audiovisual hegemónica como la pedagogía del poder (Möller, 2002) y su consumo como un espacio de aprendizaje de la colonialidad del ver (Barriendos, 2011) permite articular las perspectivas disciplinares de los estudios cinematográficos, los estudios visuales, la educación para los medios y la educación orientada a construir interculturalidad y decolonialidad, con el propósito de ensayar estrategias político-pedagógicas para educar miradas en resistencia que visibilicen y cuestionen la reproducción simbólica de desigualdades en el acceso al reconocimiento social de identidades y culturas diversas. La pluralidad de voces y miradas, la diversidad 
de identidades, culturas y trayectorias de vida de los aprendices facilita que se produzcan fructíferos contrastes en la interpretación colectiva de las obras cinematográficas analizadas, es decir, la pluralidad de los miembros de la comunidad de práctica contribuye a evidenciar la calidad de constructo de todo discurso.

Ahora bien, con respecto al rol del curso Gramática del Cine Sonoro en la Especialización en Estudios Cinematográficos, constatamos que puede ser un eje fundamental en la construcción de los proyectos de análisis y creación cinematográfica de los aprendices, puede detonar la creación de textos escritos y audiovisuales desde posicionamientos políticos críticos del poder; con lo cual se hace evidente la avidez de ciertos estudiantes por hacer del análisis y la creación cinematográfica instrumentos de comunicación política sobre problemáticas diversas presentes en sus contextos de origen. Por ello, consideramos pertinente que, en el marco de su proyecto institucional orientado a impulsar el enfoque intercultural de modo transversal en todo el quehacer de la Universidad Veracruzana, se implementen experiencias de aprendizaje similares a la estudiada en este artículo en sus programas de grado.

En especial, resulta sencillo adaptarlo a los intereses temáticos de programas como Antropología Social, Artes Visuales, Ciencias de la Comunicación, Diseño de la Comunicación Visual, Enseñanza de las Artes, Fotografía, Geografía, Gestión Intercultural para el Desarrollo, Historia, Pedagogía, Psicología, Sociología, Teatro y Trabajo Social. Es importante resaltar que la selección de películas puede adaptarse al contexto específico en el que se implemente el curso, para incluir la representación de otras identidades, por ejemplo, la representación de afrodescendientes, de miembros de colectivos LGTBIQ o de personas con discapacidades. En cualquier caso, el contraste entre narrativas creadas desde posicionamientos políticos radicalmente distintos, en conjunto con el contraste entre las diversas perspectivas de los aprendices en los diálogos, son fundamentales para detonar reflexiones críticas sobre las desigualdades de origen colonial que estructuran las relaciones sociales del mundo contemporáneo.

Consideramos importante que Angélica, en las dos experiencias educativas que imparte actualmente en la sede Grandes Montañas de la Universidad Veracruzana Intercultural, Medios de Comunicación y Organización Social y Participación, ya ha integrado estrategias de aprendizaje similares a las que experimentó en Gramática del Cine Sonoro, por ejemplo, analizar Tonta, tonta pero tanto y La hija de la laguna. El propósito es, por un lado, reflexionar sobre la importancia de las formas de representación en los audiovisuales y promover que los aprendices construyan discursos que dignifiquen y den voz a sus comunidades, y, por otro, analizar un proceso organizativo y la lucha por la defensa del territorio, además de contrastarlo con procesos similares que tienen lugar en su territorio. También es destacable que Silvia (Teatro) ya no pueda "ver una película de la misma manera en la que lo hacía antes", que trate de ver qué le quieren contar sus 
imágenes e identificar qué le cuentan los sonidos, y que intente fomentar en sus estudiantes de preparatoria "esa pasión por ver los detalles, más allá de sentarse a comer palomitas y disfrutar el filme [...] ser sensible a 'el todo' de lo que me quieren contar y transmitir eso en las generaciones que vienen detrás" (Silvia, comunicación personal, 22 de abril del 2019).

En suma, los resultados de nuestra investigación hacen evidente que educar miradas para resistir la colonialidad del ver no solo es necesario sino posible, la universidad pública puede generar espacios y procesos para deconstruir representaciones coloniales, racistas o patriarcales de la otredad y fortalecer las identidades y culturas de todos quienes participan en ellos, para hacer un análisis crítico de la cultura audiovisual promovida desde el poder. Es relativamente sencillo integrar y analizar una muestra cinematográfica que permita visibilizar la colonialidad del ver en su conjunto y el diálogo con películas de orígenes culturales, perspectivas y posicionamientos políticos diversos. Puede generar reflexiones críticas sobre cómo se representan en el cine identidades y culturas desde cuotas desiguales de poder, además, de incidir positivamente en la construcción de capacidades críticas y creativas de los aprendices. Impulsar procesos de alfabetización audiovisual en clave decolonial es una tarea al alcance de casi cualquier comunidad de práctica, en casi cualquier contexto histórico-social, y puede ser una herramienta para construir el bien común con base en el reconocimiento igualitario en la diversidad.

\section{REFERENCIAS}

Baca Feldman, C. F. (2015). Experiencias resonantes de comunicación en pueblos indígenas de Oaxaca, México. Universitas Humanística. 81: 256-277.

Barbas Coslado, A. (2012). Educomunicación: desarrollo, enfoques y desafíos en un mundo interconectado. Foro de Educación. 14: 157-175.

Barnechea, M.M. y Morgan, M.L. (2010). La sistematización de experiencias: producción de conocimientos desde y para la práctica. Tendencias y Retos. 15: 97-107.

Barriendos, J. (2011). La colonialidad del ver: hacia un nuevo diálogo visual interepistémico. Nómadas, 35.

Bidaseca, K. y Vázquez Laba, V. (2011). Feminismos y (des)colonialidad. Las voces de las mujeres indígenas del sur. Temas de mujeres. Año 7. 7: 24 - 42.

Bonfil Batalla, G. (2010). México profundo, una civilización negada. México: Debolsillo.

Brea, J. L. (2005). Los estudios visuales: por una epistemología política de la visualidad. En Brea, J. L. (ed.). Estudios visuales: la epistemología de la visualidad en la era de la globalización. Madrid: Akal. 
Díaz, C.J. (2010). Hacia una pedagogía en clave decolonial: entre aperturas, búsquedas y posibilidades. Tabula Rasa. 13, 217-233.

Domínguez, M.C., Medina, A. y Sánchez, C. (2011). La Innovación en el aula: referente para el diseño y desarrollo curricular. Revista Perspectiva Educacional. Vol 50, 1, 61-86.

Dussel, I. (2006). "Educar la mirada: Reflexiones sobre una experiencia de producción audiovisual y de formación docente". En: Dussel, I. y Gutiérrez, D. (Comp.). Educar la mirada. Políticas y pedagogías de la imagen. Buenos Aires: Manantial, FLACSO-OSDE.

Fueyo, A. (2003). Alfabetización audiovisual: una respuesta crítica a la pedagogía cultural de los medios. En Aparici, R. (Coord.). Comunicación educativa en la sociedad de la información. Madrid: UNED.

Grosfoguel, R. (2012). El concepto de "racismo" en Michel Foucault y Frantz Fanon: ¿teorizar desde la zona del ser o desde la zona del no-ser? Tabula Rasa. 16, 79-102.

Hobbs, R. (2011). The State of Media Literacy: A Response to Potter. Journal Of Broadcasting \& Electronic Media. 55, 3: 419-430.

Kellner, D., y Share, J. (2007). Critical media literacy, democracy, and the reconstruction of education. En Macedo, D. y Steinberg, S.R. (Eds.). Media literacy: A reader. New York: Peter Lang Publishing.

León, C. (2012). Imagen, medios y telecolonialidad: hacia una crítica decolonial de los estudios visuales. Aisthesis, Revista chilena de investigaciones estéticas, número 51.

López Hurtado, L. E. (2009). Interculturalidad, educación y política en América Latina: perspectivas desde el sur, pistas para una investigación comprometida y dialogal. En: López Hurtado, L. E. (ed.). Interculturalidad, educación y ciudadanía. Perspectivas latinoamericanas. La Paz: PROEIB, Plural editores.

López Monroy, M. (2006). “La producción de una utopía o secretos para elaborar campanas: notas sobre el conocimiento cinematográfico y las escuelas de cine", en Cuadernos de Estudios Cinematográficos. No. 9. Enseñanza de la cinematografía. México: UNAM.

Méndez-Tello, K. M. (2019). El cine-video indígena. Procesos paralelos de las(os) realizadoras(es): Análisis de producciones indígenas de Ojo de Agua Comunicación. Ensayo final, Especialización en Estudios Cinematográficos. Facultad de Artes Plásticas. México: Universidad Veracruzana.

Mijangos Zúñiga, D. (2019). Ciro Guerra. Un cine propiamente colombiano. Ensayo final, Especialización en Estudios Cinematográficos. Facultad de Artes Plásticas. México: Universidad Veracruzana. 
Morduchowicz, R. (2008). Introducción. Los jóvenes y las pantallas: nuevas formas de sociabilidad. En Morduchowicz, R. (Coord.). Los jóvenes y las pantallas. Barcelona: Gedisa.

Möller, C. (2002). La pedagogía del poder. Historia de la educación: Revista interuniversitaria. $21,241-260$.

Primer Foro de Alfabetización Mediática e Informacional en Latinoamérica y el Caribe (Amilac). (2014). Declaración México. Tlatelolco, México, el 11 de diciembre del año 2014. Consultado el 15052019, disponible en https://bit.ly/2LVJjH4

Quijano, A. (2000). Colonialidad del poder y clasificación social. Journal of world-systems research. VI. 2, 342-386.

Santana Marroquín, T. (2007). Análisis de discurso denotativo y connotativo de producciones de video indígena de Ojos de Agua Comunicación. Tesis Licenciatura en Ciencias de la Comunicación, Departamento de la Comunicación, Escuela de Ciencias Sociales, Artes y Humanidades, Universidad de las Américas Puebla.

Shohat, E. y Stam, R. (2002). Multiculturalismo, cine y medios de comunicación: crítica del pensamiento eurocéntrico. Barcelona: Paidós.

Torricella, A. (2018). De viajes teórico-metodológicos y mapas. Bitácora de una travesía entre la noción de representación visual como reflejo hacia la de práctica y su aplicación en un caso de estudio con fotografías familiares personales. Empiria. Revista de Metodología de Ciencias Sociales. 40: 41-64.

Wenger, E. (2001). Comunidades de práctica: aprendizaje, significado e identidad. Trad. de Genís Sánchez Barberán. Barcelona: Paidós.

Zárate-Moedano, R. (2018). Alfabetización mediática decolonial para la formación de miradas antirracistas en la Universidad. Revista científica Ra- Ximhai. 14 (2): 201-219.

Zavala, L. (2017). Los estudios sobre cine en México al inicio del nuevo siglo. Miguel Hernández Communication Journal. 8. 2: 51-84.

\section{Filmografía}

Amador, C. (productora) y Barriga, G. (director). (2007). Hamac Caziim (Fuego Sagrado) [documental]. México: Centro Universitario de Estudios Cinematográficos / Universidad Nacional Autónoma de México.

Aranoa, F. (productor) y Aranoa, F. (director). (2005). Princesas [cinta cinematográfica]. España: Reposado Producciones / Mediapro/ Antena 3 Televisión/ Canal + España. 
Aubry, K., Ford, F. (productores) y Ford, F. (director). (1979). Apocalypse Now [cinta cinematográfica]. Estados Unidos: Zoetrope Studios.

Bonilla, H., Trujillo, V. (productores) y Fons, J. (director). (1989). Rojo Amanecer [cinta cinematográfica]. México: Cinematográfica Sol.

Chaplin, C. (productor) y Chaplin, C. (director). (1940). El gran dictador [cinta cinematográfica]. Estados Unidos: United Artists.

Cinta Robles, A., Santiago Francisco, J. y Zárate Moedano, R. (productores) y Santiago Francisco, J. y Zárate Moedano, R. (directores). (2015). Existe cuando hablas [documental]. México: Cinta Robles, A. / Santiago Francisco, J. / Zárate Moedano, R.

Del Toro, F., Welch, F. (productores) y Del Toro, F. (director). (2005). Cicatrices [cinta cinematográfica]. México: Armagedon Producciones.

Fink, J. (productor) y Fernández, E. (director). (1943). María Candelaria [cinta cinematográfica]. México: Films Mundiales.

Frigola, N. (productora) y Cabellos, E. (director). (2015). La hija de la laguna [documental]. Perú: Guarango - Cine y Video.

García, S. (productor) y Bollain, I. (directora). (2003). Te doy mis ojos [cinta cinematográfica]. España: Producciones La iguana S- L / Alta Producción.

Gordon, J. (productor) y Bollain, I. (directora). (2010). También la lluvia [cinta cinematográfica]. España: Coproducción España- Francia- México; Moreno Films.

Lipkies, I. (productor) y Cortés, F. (director). (1972). Tonta, tonta pero no tanto [cinta cinematográfica]. México: América Films / Diana Films / Teleprogramas Acapulco.

Llosa, C., Chavarrias, A., Morales, J. (productores) y Llosa, C. (directora). (2006). Madeinusa [cinta cinematográfica]. Perú: Coproducción Perú-España; Oberón Cinematográfica S. A./ Vela Producciones/ Wanda Visión.

Paul, R., Granderath, C., Ronson, R. (productores) y Al-Mansour, H. (directora). (2012). La bicicleta verde [cinta cinematográfica]. Arabia Saudí: Copodrucción Arabia Saudí - Alemania; Highlook Comunications Group / Razor Film.

Polgovsky, E. (productor) y Polgovsky, E. (director). (2008). Los herederos [documental]. México: Tecolote Films.

Pontecorvo, G. (productor) y Pontecorvo, G. (director). (1966). La batalla de Argel [cinta cinematográfica]. Italia: Coproducción Italia- Argelia; Igor Film.

Riefenstahl, L. (productor) y Riefenstahl, L. (director). (1935). El triunfo de la Voluntad [cinta cinematográfica]. Alemania: Reichsparteitag-Film. 